International Journal of Applied Linguistics \& English Literature

ISSN 2200-3592 (Print), ISSN 2200-3452 (Online)

Vol. 1 No. 7; November 2012 [Special Issue on Applied Linguistics]

\title{
'Farm' Animal Metaphors in Malay and Arabic Figurative Expressions: Implications for Language Learning
}

\author{
Sabariah Md Rashid (Corresponding author) \\ Faculty of Modern Languages and Communication \\ Universiti Putra Malaysia \\ 43400 UPM Serdang, Selangor \\ Tel: 603-89468778 E-mail: sabrina@fbmk.upm.edu.my \\ Pabiyah Hajimaming \\ Faculty of Modern Languages and Communication \\ Universiti Putra Malaysia \\ 43400 UPM Serdang, Selangor \\ Tel: 603-89468678 E-mail: pabiyah@fbmk.upm.edu.my \\ Nurul Nadia Muhammad \\ Faculty of Modern Languages and Communication \\ Universiti Putra Malaysia \\ 43400 UPM Serdang, Selangor, Malaysia \\ Tel: 013-9663244_ E-mail: nad286@yahoo.com
}

Received: 16-10- 2012

Accepted: 23-11- 2012

Published: 25-11- 2012

doi:10.7575/ijalel.v.1n.7p.33

URL: http://dx.doi.org/10.7575/ijalel.v.1n.7p.33

The research is financed by Research University Grant Scheme (RUGS) of Universiti Putra Malaysia.

\begin{abstract}
Animals are commonly used in figurative expressions, such as proverbs and idioms. Their features, characteristics, and/or behaviours are employed as metaphors to convey certain meanings. This study sought to examine animal metaphors of Malay and Arabic figurative expressions. Data examined comprised Malay figurative expressions such as simpulan bahasa (two-word idioms) and peribahasa (proverbs), as well as Arabic figurative expressions such as istiarah (proverbs) containing 'farm' animals, such as cow, donkey, horse and goat. The analysis focused on the description of animal images used in the expressions and their connotations. Findings of the study revealed some similarities and differences, in terms of the images and connotations used in the expressions of the two languages, which may be attributed to cultural differences. The differences reflected in the Malay and Arabic figurative expressions may contribute to the difficulty in grasping the meanings of the expressions amongst learners of these languages. Thus, it is essential that learners of each language be exposed to the elements related to the cultural differences of the two languages to help them understand the expressions better and become effective language learners.
\end{abstract}

Keywords: Animal metaphors, Images, Connotations, Language learning

\section{Introduction}

Metaphors as a figure of thought rather than language ornaments per se have been the subject of investigation for the last three decades. Research on metaphors has examined the use of specific metaphors in various contexts and their source domains in different languages. Domains that have been identified as source of metaphors 
International Journal of Applied Linguistics \& English Literature

ISSN 2200-3592 (Print), ISSN 2200-3452 (Online)

Vol. 1 No. 7; November 2012 [Special Issue on Applied Linguistics]

include food, time, and animals. Animal metaphors in various languages have been examined in various languages, among others, English (Thornton, 1999; Rodríguez,, 2009) Spanish (Rodríguez, 2009), English and Spanish (Fontecha \& Catalán, 2002), Hungarian (Kleparski 2002), Chinese (Wang \& Dowker 2008; Kiełtyka \& Kleparski, 2009), Persian (Estaji \& Nakhavali, 2011) and Malay (Imran Ho-Abdullah, 2011). To date, however, there has been scarcely any study that has contrastively examined expressions related to animal metaphors in Malay and Arabic. A study on animal metaphors in Malay figurative expressions was conducted by Imran Ho-Abdullah (2011), but the study was limited to data on the use of dog in Malay proverbs. This study aimed at examining animal metaphors in Malay and Arabic figurative expressions with reference to some metaphorical expressions in English. It focused on describing the images and connotations, i.e. positive or negative, associated with farm animals, such as horse, cow, donkey and goat. A contrastive semantic analysis of animal metaphors in the two unrelated languages can shed light on cross-cultural differences, which in turn may be beneficial for learners of either language.

\section{Literature Review}

Research on animal metaphors has revealed the use of different categories related to animals. One common category is that of mammals, which dominate quantitatively in English historical animal metaphors (Thorntorn, 1999). Thorntorn attributes this to "their widely understood similarity, familiarity and closeness to mankind" (Kiełtyka \& Kleparski, 2007, p.89). In the same vein, research has found that names of animals have been used in various metaphorical expressions referring to people, denoting some derogatory characteristics.

A study on animal imagery in ten Arabic poems by two contemporary Bedouin poets revealed the use of metaphors and similes drawn from the animal kingdom, specifically animals of the desert (Holes \& Abu Athera, 2009). In the poems, politicians are compared to falcons, sparrows, ostriches and mules among many other animals, not exclusively, animals of the desert ( 37 animals).

A study by Peled-Shapira (2009) focused on metaphors derived from the animal world in the narrative works of the twentieth century exiled Iraqi Communist writer Ghaib Tu Ma Farmasi. The animals were used to describe the relationship between intellectuals and authorities in the mid-twentieth century Iraq against the backdrop of the conservative and conformist's use of metaphor in classical Arabic literature. The animal metaphors were used to depict the writer as leftist intellectual presented by the government.

On a different note, a study of animal metaphors in the Yorùbá language highlights the stylistic and communicative potentials of these metaphors (Ọlátéjú 2005). Specifically, the animals - domestic and wild, involved in metaphors and their individual distinctive characteristic features that motivate their metaphorical interpretations are highlighted. Findings of the study revealed that the sources of animal metaphors were located in three areas, namely: the Yorùbá naming culture, animal characteristic habits and behaviour, and the Yorùbá poetry. Animal metaphors involve transference of meanings, and whatever meanings or interpretations are assigned to a particular animal metaphor, are culture and context dependent. The study concludes with stylistic and communicative functions of animal metaphors, with the submission that stylistically animal metaphors contribute to aesthetics and poetic elegance of literary texts through their lexical tones, which can be stylistically manipulated.

Another study examined animal metaphors for women in English and Spanish (Rodriguez, 2009). The objectives of the study were two fold, i.e. to explore perceptions of womanhood through animal metaphors, as well as to compare figurative uses of animal names applied to females in both English and Spanish. The study found that animal metaphors reinforced the stereotypical view of the female sex. In terms of their habitat, it appears that, whereas the names of certain pet and farmyard animals carry positive connotations, all the animals within the wild category transmit undesirable associations. Besides that, as far as the social role is concerned, pet and farm animals stress the idea that women are conceived to entertain and provide company, in the case of the former, and to render service to man either by providing food or begetting children, in the case of the latter.

A study that focused on Hungarian animal metaphors revealed resemblances to the body of animal metaphors that have occurred in the history of English and other European languages, i.e. the conceptual category of MAMMALS is the main category that has undergone a shift in the usage (Kleparski, 2002). This was attributed to the fact that mammals are most familiar to mankind. Findings of the study illustrate that the animal names are used to denote certain behavioural characteristics of people that are often depreciative, i.e. those associated with negativity or "a quality that is neutral of favourable in an animal, but becomes reprehensible in a human being or human beings" (Kleparski, 2002, p.27). Kleparski emphasised that there was a tendency to ascribe derogatory features in people by means of animal imagery. 
International Journal of Applied Linguistics \& English Literature

ISSN 2200-3592 (Print), ISSN 2200-3452 (Online)

Vol. 1 No. 7; November 2012 [Special Issue on Applied Linguistics]

Another similar in-depth study on the shifts of Chinese zoosemy (animal metaphor) (Kiełtyka \& Kleparski, 2007), particularly the conceptual category DOMESTICATED ANIMALS confirmed the findings of others (e.g, Thornton 1989; Kleparski 2002; and Kieltyka \& Kleparski 2002). It was found that the conceptual dimension APPEARANCE/PHYSICAL CHARACTERISTICS seems to play a crucial role in the process of zoosemic extension in Chinese. Another group of Chinese animal metaphors are clearly triggered via the activation of various attributive values specifiable for the conceptual dimension BEHAVIOUR/CHARACTER (p.90). These dimensions are mainly used in the negative sense, representing the metaphorically concept INFERIORITY and LOW SOCIAL STATUS.

This inferiority and negativity associations are also evident in the findings of a study on dog metaphors in Malay proverbs. In this study, Imran Ho-Abdullah (2011) examined the role of cognitive mechanisms, namely the Great Chain of Being metaphor and the specific stands for the generic metonymy in Malay proverbs relating to dogs. The study revealed that the dog is often mapped onto human beings. Findings of the study illustrate differences in the metaphorical schemas and meanings of animal proverbs related to dog - ones which are typically "either weak, despised, bad or ignorant" (p.126), but in line with the findings of other studies on animal metaphors, in that, they are associated with negativity.

In another study on cross-cultural comparison of Persian and English, a contrastive analysis of the interpretations of animal metaphors in the two languages was conducted by Esmail Faghih (2001). This study aimed to find out whether and to what extent the animal metaphors and specially their interpretations are similar in Persian and English. The study also aimed to find out whether animal metaphors have positive connotations or not. The comparison and contrast revealed that despite outstanding agreements in some cases there are also differences in the animal terms and the interpretations assigned. From the viewpoint of contrastive analysis, the study revealed that when the intended meaning in L1 and L2 are the same but the formal devices to express them differ, negative transfer will take place. The study emphasised the role of immediate, remote and especially cultural context in the interpretations of animal metaphors and hence in the Teaching of English of a Foreign Language (TEFL).

\section{Methodology}

Data of the study comprised Malay and Arabic figurative expressions that contain animal metaphors. The data were gathered manually from various sources, namely the electronic databases - the electronic database on Malay proverbs and Dewan Bahasa dan Pustaka corpus, as well as various books on Malay proverbs and idioms. All the instances of figurative expressions which contained the names of animals, in particular, farm animals were extracted and recorded. The data consisted of 930 animal metaphor expressions in Malay and Arabic. The initial data focused on data that comprised the names of farm animals, such as buffalo, cow, goat, donkey and horse. In total, approximately 100 instances of figurative expressions which utilise the names of such animals were identified. From the collated data, four types of farm animals were further selected for analysis, namely horse, cow, goat and donkey. Only animals that have common figurative expressions in both languages (being used widely in the society) were included in the analysis of the present study. The data were analysed qualitatively using the Lakoffian framework $(1980 ; 1989)$ focusing on the images, mapping and evaluation embedded in the meaning of the respective expressions. For the purpose of analysis and discussion, each metaphorical expression in Malay and Arabic is followed by a literal translation (written in parentheses). In addition, small capitals are used to denote a concept or conceptual metaphor, a convention commonly used in cognitive semantics and cognitive linguistic research articles.

\section{Results}

The analysis of the data revealed various secondary metaphorical meanings associated with the expressions of the two languages. Images related to the behaviour or characteristics of the animals are manifested in the expressions of both languages. To illustrate the differences and similarities in the use of animal metaphors in the two languages, the discussion of a representative sample of the data from both Malay and Arabic is included in the paper.

\subsection{Horse metaphors in Malay and Arabic expressions}

In Malay society, horse is used in sports, agriculture, as well as for practical purposes such as aiding the policemen in their tasks. Because of its closeness to human, horse has been used in Malay proverbs. The data illustrate that most of the time, horse is associated with negative meanings in Malay. For example, the Malay two-word figurative expression (simpulan bahasa) kuda belang (horse stripe) refers to a man who is very rude 
International Journal of Applied Linguistics \& English Literature

ISSN 2200-3592 (Print), ISSN 2200-3452 (Online)

Vol. 1 No. 7; November 2012 [Special Issue on Applied Linguistics]

and impolite. As we all know, zebra (in Malay known as kuda belang) is a wild animal and this characteristic is transferred to the character of a human being. Another negative meaning associated with horse in Malay figurative expressions is its use as a tool of manipulation. For instance, kuda tunggangan (horse ride) means a person who is used for an undesirable goal. Here, horse is used in a negative sense as a means of manipulation. This usage could perhaps be derived from the fact that in many societies, horse is used commonly as a means of transportation to carry their things. However, a positive characteristic is also manifested in Malay expressions related to horse metaphors. This can be seen in the proverb kuda yang pantas tiada berkehendakkan cemeti (A fast horse does not need a whip), which means people who work hard and know how to do the work well do not have to be monitored denoting a positive behavioural characteristic.

In Arab society, horses are also often associated with positive values such as obedience, strength, and courage. The horse is regarded as a very important animal in their lives. As the condition in the desert that is rather dry and difficult for the people to obtain resources, this animal is needed by the community. Horses are often used as a mount for the purpose of hunting, moving from one place to another place. Thus, the Arabs are very proud of owning a horse. Other positive qualities associated with the horse are obedience and loyalty. This can be seen in the proverb Athwa 'min faras, wa min Kalb (more loyal than horses and dogs). In the English community, the dog is an animal that is often associated with the nature of obedience. However, in the Arab community, other than dogs, horses are also associated with the nature of allegiance and loyalty to their masters. Apart from its loyalty, this animal is also associated with fast movement. Such a case can be explained by the proverb Asyad min faras (more than the speed of a horse) which maps the characteristic of a horse that moves faster and quicker than some other animals. Therefore, for those who do the job quickly and with speed will be associated with this proverb. Other than that, the horse is also associated with negative characteristics such as quick-tempered. This can be seen in the proverb Ghadhabu al khail' ala al lujum (horse anger upon its bridle). This proverb is aimed at people who get angry for no reason, an image mapped onto the condition of an annoyed horse which has a bridle around its mouth.

Contrastively in English, expressions associated with horse metaphors tend to have negative meanings. For example, in English there are expressions such as 'horse around' (behave noisily and stupidly), 'horseplay' (rough, noisy behaviour)

\subsection{Goat metaphors in Malay and Arabic expressions}

Goat is an animal that is commonly reared by Malay community for its meat and milk. The animal is often associated with negativity in Malay figurative expressions, such as proverbs and simpulan bahasa. For example the simpulan bahasa "kambing hitam" (black sheep) refers to a person who is blamed for something bad that she or he did not commit. Its meaning is somewhat equivalent to the meaning of 'scapegoat' in English. Interestingly, it takes on a different meaning compared to the meaning associated with the English expression 'black sheep', i.e. someone who brings shame to a family. The meaning of 'black sheep' in Malay is perhaps associated with the colour black, a symbol of evil or death. Here the characteristic of the goat, i.e. appearance is mapped onto the characteristic of a person, which is bad. Besides that, in the Malay idiom jiwa kambing (goat's soul), goat is associated with the negative meaning 'cowardice'. Thus a person who has a goat's soul is regarded as a coward. This meaning is perhaps derived from the behavioural characteristic of the goat itself, which is scared of water. This characteristic is mapped onto the character of a human being to mean a coward. Another negative meaning associated with this animal is manifested in the proverb bagai kambing dimandikan pagi (like a goat which is bathed in the morning). The proverb denotes a person who is very reluctant or unwilling to carry out a task. In this proverb, the behavioural characteristic of a goat that dislikes or is scared of water and unlikely to go near the water, regardless of whatever circumstances (showing strong refusal) is transferred to the personality of human being which denotes laziness.

Similarly, in Arabic proverbs, goat is associated with negativity. Such a case is manifested in the proverb, zallat al ghanam 'abithatan wahidah (goat herd remains one), which refers to a person who is easily influenced by negative things. The behavioural characteristic of a goat's herd that stay together in the herd is mapped onto the behavioural character of a person who is gullible and prone to act undesirably. Another Arabic figurative expression that relates to bad behaviour is ya syah aina tazhabin? Qalat ujaz ma'a al majzuzin" (O sheep, where are you going? It said: I will shear with those who are sheared). This expression refers to a person who is unsure of what action to take as manifested by the sheep's behaviour. Like the sheep, when asked where or what a person would do, she or he would is heading to, she or he will answer in uncertainty. Interestingly, in Arabic, goat or sheep also has somewhat positive connotations. This is manifested in the Arabic proverb tahta jild al 
International Journal of Applied Linguistics \& English Literature

ISSN 2200-3592 (Print), ISSN 2200-3452 (Online)

Vol. 1 No. 7; November 2012 [Special Issue on Applied Linguistics]

dha'n qalb al azub (a wolf's heart under a sheep's skin), which means a two-faced person. This is similar to the meaning of an equivalent English proverb, "a wolf in a sheep's clothing". What is obvious in this proverb is the contrast in meaning associated to the sheep (good) and wolf (bad). However, in general, the meaning of the proverb is still regarded negative as it is typically associated with a deceitful behaviour. Similarly, English has negative meanings associated with the use of sheep metaphor, such as 'he's a sheep' (unthinking imitator or overly obedient person) and 'mutton dressed as lamb' (older woman trying to look young).

\subsection{Cow/bull metaphors in Malay and Arabic expressions}

Besides the horse and goat mentioned previously, cow is also among the farm animals that is commonly reared not only by the Malay community, but also other communities in the world. It helps human being in the farm work like ploughing and also as a means of transportation. The cow's meat can be eaten and its milk is extracted for dairy products. Despite the benefits that human beings gain from this animal, cow is always associated with negative meanings in Malay. An example of this is invoked in the simpulan bahasa "lembu kenyang" (a full cow), which refers to a person who is lazy, stubborn and not bothered. If we look closely at a cow when it is full, it is unlikely to move around and it would just sit still at one place. The observed behaviour of the full cow is mapped onto the human being's undesirable character that denotes laziness and stubbornness. Other than that, bull is also used in Malay proverbs to signify weakness. For instance, the proverb laksana lembu kasi: galak saja tiada melawan (like bull neutered; fierce but does not fight back) is meant for someone who is physically fit but a coward. The meaning is derived from the observation of the behaviour of a bull, which is neutered and will be passive, unlike a typical bull. This behaviour is transferred to a human being character, which physically looks fit and strong, but is actually weak and would avoid fighting and anything risky so as not to hurt himself/herself. The animal cow is also used negatively in the proverb jadi lembu (become cow) which means enslaved. As mentioned earlier, although cows are beneficial to human beings, i.e. as a means of transportation, food provider (meat and milk), as well as an aid in farm work, it is regarded negatively, in that it is a bovine animal and used to the fullest to a human advantage. This behaviour is mapped onto the character of a human being which symbolises slavery.

Similarly in Arabic figurative expressions, cow is often used for negative references. This can be seen in some proverbs that are expressed by the Arabs. One of them is Kathaur yudhrab Lamma 'afat al baqar (As the bull was beaten when the heifers refuse to drink water) refers to a person who receives a punishment for others' offense. This is semblance of a situation where bulls get beaten up when the heifers refuse to drink the provided water. Besides that, in Arabic, cow also symbolises a woman who is regarded of having 'lower' traits in comparison to another woman. This meaning is perhaps related to the scenario in the Arab "Jahiliyah" society, whereby a man wishes to take another woman as his new wife or partner, he would utter: al Ziba ala al baqar [I choose a deer (rather than) a cow], which means that the man clearly indicates that he wants to leave his wife for another supposedly better woman. In this case, the first wife is relegated to a 'lower' position than the new wife. Another expression that has a negative meaning is al Kilab ala al baqar [(he sent) a dog to a cow], which refers to a person who is not really concerned about the situation, similar to a situation when a dog is sent to a cow, it would not have any effect on the cow. This is also expressed in the Malay proverb Dogs bark hill, (hill) will not collapse with a similar meaning.

As evident in the above Malay and Arabic expressions of cow metaphors, negative meanings associated with cow metaphors are also common in English as in the examples: 'she is a cow' (she is fat/unpleasant) and 'that child is bull-headed' (stubborn/obstinate).

\subsection{Donkey metaphors in Malay and Arabic expressions}

Like other farm animals described above, donkey is used negatively in Malay proverbs. It connotes stupidity and ignorance. For example, the proverb keldai hendak dijadikan kuda (ass want to be made horse) means a stupid person who wants to be treated like a wise man. In this proverb, donkey symbolises stupidity while horse symbolises intelligence. Thus, the Malay society ascribes the characteristic of the donkey to that of negative traits, i.e. stupidity as reference to people's personality. This animal is also associated with ignorance, which can be seen in the expression keldai membawa kitab (ass/donkey carries a book), which refers to one who is knowledgeable but does not applying his/her knowledge accordingly. Here, the image of the donkey carrying a book without benefitting from it is mapped onto a person with similar characteristic, which is associated with ignorance. Thus, in the Malay culture, when we refer to somebody as an ass carrying a book, we mean that that the person is ignorant. This is similar to the meaning ascribed to the use of donkey metaphors in English 
International Journal of Applied Linguistics \& English Literature

ISSN 2200-3592 (Print), ISSN 2200-3452 (Online)

Vol. 1 No. 7; November 2012 [Special Issue on Applied Linguistics]

expressions. For example, when someone is referred to as a donkey in English, it means that the person is silly or stupid. A 'donkey-work' means a hard or boring part of a job (Goatly, 2006).

In contrast to the use of donkey in Malay and English, in Arabic proverbs, donkey is associated with both positive and negative meanings. Some of the characteristics associated with this animal are patience and physical endurance. The negative characteristic portrayed by this animal is stupidity, and so forth. For example, in the proverb: Ajhal min Himar (more stupid than ass/donkey), a donkey is regarded as a stupid animal and people use this characteristic to illustrate the ability of the human mind. The Arabs associate stupidity with the trait of the donkey, which contrasts with the Malay community, which relates stupidity to the cow. Apart from this characteristic, the Arabs also use the donkey to refer to other negative meanings. Such a case can be seen in the proverb Urbuth himarak fainnahu mustanfir (fasten your donkey, surely it is wilder). This proverb refers to people who like to hurt others. The meaning is associated with the image of restricting the movement of a donkey by tying it up or putting it on a leash. This image is mapped onto a similar condition in which a person who must be prevented from hurting others by restraining them. Interestingly, the donkey is also associated with a positive meaning in Arabic figurative expressions. In the positive sense, this animal is described as having the virtue of patience as manifested in the proverb Asbar min Himar (more patient than a donkey) to connote the patient characteristic of an individual. This is perhaps mapped onto the trait of the donkey, which is able to endure the task of carrying a heavy load on his back for a long period and distance.

\section{Discussion}

The analysis of the data has illustrated some differences and similarities with regards to the use of farm animals in both Malay and Arabic figurative expressions. These differences can be attributed to the cultural and geographical differences of both Malay and Arabic. A number of researchers have hypothesised that cultural differences, in particular with respect to metaphors, may lead to problems in learning a second or foreign language. Hogan (2009) posited that idiomatic expressions are learnt in the same manner as literal language. He emphasised that a greater amount of time is required to learn the figurative speech of a target language, as this process presupposes a substantial degree of command of the literal aspect of the foreign language, or in other words, a higher cognitive ability.

To understand and be able to use metaphorical expressions appropriately requires a higher cognitive ability. This is because its abstract nature is different from that of literal language, whereby the meaning can be inferred from the combination of words that constitute the expressions. Thus, expressions that are familiar to learners of a target language or those that have similar images with that of the target language would be easier to understand and used appropriately. However those that are different may pose learning difficulties to the learners.

Since language is associated to the culture in which it evolved, it is also imperative for a non-native speaker to have some degree of immersion or exposure to the images that are unfamiliar to them. Thus, for English as a second or foreign language (ESL/EFL) learners who may want to convey their message via metaphorical expressions in a foreign language, or using them in a different cultural context from which it evolved, it is necessary for them to fully understand the images and meanings associated with the respective expressions. In this light, if two languages have radically different conceptual systems, then speakers of one language cannot understand the other language because of the unfamiliar metaphors to the learners. It follows that, if languages have different conceptual systems, then somebody who speaks one language will find it a challenge to grasp the meaning conveyed in the metaphorical expressions of the target language.

Often figurative expressions of a particular language are motivated by experiences of the community which uses the language and the experiences are manifested in certain expressions of the language. As in the case of Malay and Arabic, the two languages are unrelated and different culturally. As seen in the expressions exemplified in the study, the use of the same animals in both language communities conveys different meanings. In some cases, although the meaning conveyed is the same, the metaphors that are manifested in the expressions are different as illustrated by the connotation of stupidity in the two languages. Whilst the negative meaning of stupidity is associated with the animal cow in Malay, stupidity in Arabic is ascribed to the donkey. In the process of learning a second or foreign language; therefore, language learners must understand the target language culture so as to facilitate the learning of the language to avoid any misinterpretation of the meaning conveyed by a figurative expression. Faghih (2001) points out that one of the troublesome areas of EFL for Iranian students and especially novice translators is the figurative use of language. This problem becomes more serious if the learners are not exposed to the target language and culture to which it is attached. Thus in order to gain communicative competence in the target language, it is crucial that the learners not only learn the denotative meanings of words 
International Journal of Applied Linguistics \& English Literature

ISSN 2200-3592 (Print), ISSN 2200-3452 (Online)

Vol. 1 No. 7; November 2012 [Special Issue on Applied Linguistics]

and expression, but also be able "to read between the lines" (p.2). To ensure that learners are able to develop their communicative competence, their attention should be drawn, among other things, to the probable differences between the different metaphors in different languages.

\section{Conclusion}

This paper has discussed that farm animals are typically manifested negatively in both Malay and Arabic figurative expressions. The negative connotations or derogatory uses of animal metaphors in the two unrelated languages provide evidence of a universal conceptual system. Culture-specificity is reflected in the linguistic realisations of the different animal metaphors and within the same animal metaphors. The varied images of animals mapped onto the expressions reflect the experiential nature of the specific language community, which constitutes different metaphorical extensions of the respective animals. This paper has also discussed the implications of the meaning and image differences related to animal metaphors of the two languages, in particular, the learning of figurative expressions. The different negative meanings denoted by the respective animal metaphors may pose some learning difficulties to the learners of either language. Thus, it is proposed that the learners be exposed to the respective images to familiarise the learners with the foreign cultural elements, which in turn will assist them to grasp the meanings of the unfamiliar expressions and subsequently enhance language acquisition. In this light, this paper has highlighted the implications of the findings of the study from the perspective of second or foreign language learning, particularly the learning of metaphorical expressions. It is also suggested that the findings of this study be taken into account in material preparation and teaching practice of a non-native target language.

\section{References}

Animal symbolism in many cultures (n.d.). Retrieved from http://www.princetonol.com/groups/iad/lessons/middle/animals2.htm Estaji, A., \& Nakhavali, F. (2011). Semantic derogation in Persian animal proverbs. Theory and Practice in Language Studies, 1(9), 1213-1217. doi:10.4304/tpls.1.9.1213-1217

Faghih, E. (2001). A contrastive analysis of the interpretations of animal metaphors in Persian and English. The Journal of Humanities, 1-15. Retrieved from The International Journal of Humanities of The Islamic Republic of Iran database

Fontecha, A. F. \& Catalán, J. (2002). Semantic derogation in animal metaphor: A contrastive-cognitive analysis of two male/female examples in English and Spanish. Journal of Pragmatics, 35(2003), 771-797.

Goatly, A. (2006). Humans, animals and metaphors. Society and Animals, 14(1), 15-37.

Hogan, W. (2009). Animals in Young Adult Fiction. Maryland, USA: The Scarecrow Press.

Holes, C. \& Abu Athera, S.S. (2007). Animal imagery in modern Bedouin poetry. Quaderni di Studi Arabi, 2, 41-52.

Imran Ho-Abdullah. (2011). A cognitive semantics analysis of Malay proverbs related to the dog (CanisFamiliaris). Journal of Language Studies, 11(1), 125-141. Retrieved from Gema Online database http://www.ukm.my/ppbl/Gema/GEMA\%20vol\%2011\%20\%281\%29\%202011/abstract\%20pp125_141.pdf Kleparski, G. A. (2002). Lusta, mint a disznó: A hunt for 'correlative' zoosemy in Hungarian and English. Studia Anglica Resoviensia 1, 16, 9-32. Retrieved from (http://www.univ.rzeszow.pl/wfil/ifa/usar1/sar_v1_01.pdf) Kieltyka, R., \& Kleparski, G. A. (2007). On the Indo-European nature of Non-Indo-European animal metaphor: The case of Chinese zoosemy. Studia Anglica Resoviensia 4, 47, 88-99. Retrieved from

(http://www.univ.rzeszow.pl/wfil/ifa/usar4/sar_v4_06.pdf)

O’Donnell, P. E. (1990). A study of French animal metaphors. The French Review, 63(3), 514-523. Retrieved from JSTOR database.

Olátéjú, A. (2005). The Yorùbá animal metaphors: Analysis and interpretation. Nordic Journal of African Studies, 14(3), 368-383.

Peled-Shapira, S., H. (2009). From conventional to personal, or: What happened to metaphor under the influence of ideology - The case of Ghā’ib Tu'Ma Farmān. Journal of Semitic Studies, 54(1), 227-249. doi:

$10.1093 /$ jss/fgn051

Rodríguez, I. L. (2009). Of women, bitches, chickens and vixens: Animal metaphors for women in English and Spanish. Culture, Language and Representation, 7, 77-100.

Wang, C. \& Dowker, A. (2007). Interpretation of animal metaphors: Evidence from Chinese and English children and adults. Paper presented at Child Language Seminar, University of Reading. 